\title{
EDITORIAL
}

\section{A VERSÃO DO ILUMINISMO EM JEAN-JACQUES ROUSSEAU}

Arlei de Espíndola

Eduardo Ferreira Chagas

Manoel Jarbas Vasconcelos Carvalho

Vigora a compreensão, em um círculo determinado, fechado, que sabe de Jean-Jacques Rousseau (1712-1778) bastante, que este pensador foi, entre os maiores de sua época, aquele que tratou de um leque mais amplo de temas, desenvolvendo um interesse variado e multifacetado, superando-os no que tange a verticalidade e complexidade enquanto filósofo, não ficando restrito ao terreno, por exemplo, das ideias políticas. Mas, escrever sobre sua produção, buscando testemunhar seu valor, riqueza, e caráter original, inovador, é um desafio e uma responsabilidade, tendo-se um propósito sério, em qualquer circunstância, ainda que esta ocasião atual traga outros elementos, adicionais, que ajudam marcar a diferença.

É oportuna a inserção do pensador genebrino, a partir de seu legado teórico, especulativo, filosófico, posto parcialmente aqui, neste rol de autores que integram, desde já, os muitos Dossiês componentes da Revista Dialectus, não tendo nada de favor nisto, aliás, de nossa parte. Isso é incomum aos iluministas, em especial de língua francesa, por abdicarem, sobretudo, de falar apenas aos iniciados, e também na medida em que conservam uma originalidade que não resulta de uma revolução na esfera da filosofia pura. Quer dizer, este reconhecimento é devido ao mérito teórico, com o qual se está autorizado homenageá-lo, valendo-se da contribuição gerada com o interesse pelas verdades a nosso alcance. Ora, Bento Prado Júnior, não por acaso, afirmou que: "ler Rousseau é, ao mesmo tempo, pensar o problema do fim da metafísica".

Pode-se admitir a presença do germe do pensamento rousseauniano no Discurso sobre as ciências e as artes, estabelecido há 270 anos, contendo seus problemas diversos, de forma seminal, é claro, desde que se veja suas obras produzindo uma ruptura com a escrita convencional, exigindo levar-se em conta o conjunto de sua produção, pois seus escritos, todos, lançam luzes uns sobre os outros. Foi este seu primeiro grande trabalho que, malgrado seu pouco rigor, suas falhas em sentido lógico, 
Arlei de Espíndola / Eduardo Ferreira Chagas / Manoel Jarbas Vasconcelos Carvalho

suas limitações conceituais, deixando a suspeita no público de ser privado até de originalidade, fazendo o clérigo Don Cajot acreditar, no século XVIII, fosse o genebrino, na verdade, um plagiador dos antigos. Mas, é aquele que lhe deu nome, fama, retirando-o para sempre do anonimato para sua alegria e desespero, ao mesmo tempo, pois nunca mais desfrutou do mesmo modo de vida, assentado na paz e na tranquilidade.

Ora, este escrito, com o qual conquistou o prêmio de moral da Academia de Dijon, de 1749, respondendo pela via negativa, isto é, o contrário do que era esperado por todos, mantendo ainda um tom oratório, servindo antes enquanto um diagnóstico das origens do mal moral, problematizando, por exemplo, o valor do progresso, da fé desmesurada na razão, empreendendo uma crítica da produção de necessidades supérfluas, artificiais, enfim, condenando a ruptura da ordem da natureza. Manifestando seu desacordo, assim, com a ordem social, política e econômica vigente, resulta, na origem, da inspiração súbita causada pela iluminação, tida a caminho de Vincennes, eternizada no livro IX das Confissões.

Pois esse último livro de edição póstuma, mas escrito no final da vida, por se considerar o valor do conjunto da produção, não guardando importância ainda menor, filosoficamente falando, discordando-se, é claro, do olhar tradicional, mantém outro tipo de natureza: é de caráter autobiográfico, literário, empreendendo o esforço de falar de si mesmo, visando o autoconhecimento, a produção do autorretrato. Essa não é uma prática estranha a Rousseau, estendendo-se ao seio de muitos de seus escritos, mas a antecipa, é certo, em vários outros menores, especificamente, com semelhante propósito: refiro, para exemplificar, apenas uma epístola, que lhe serve de introdução, as "Cartas a Malesherbes", um epigrama, o "Meu retrato", e os Devaneios do caminhante solitário, seu último trabalho em vida, realmente bem pessimista quanto ao valor da convivência social.

Mas predomina nele, neste gênero, do ponto de Rousseau, a ideia de não encontrar problema neste isolamento, na vida retirada, com a qual consolida a reforma da subjetividade na perspectiva crítica que propõe, baseando-a no sentimento da existência ou no autoconhecimento. Reza a abertura das Confissões: "que cada qual descubra, por sua vez, seu coração" diante do pai eterno "com a mesma sinceridade". Todavia, em A nova Heloísa, corroborando a ambiguidade da condição, tem-se a escrita

\begin{tabular}{|l|l|l|l|l|}
\hline Govista Dialectus & Ano 8 & n. 15 & Agosto - Dezembro 2019 & p. 8-17 \\
\hline
\end{tabular}


Arlei de Espíndola / Eduardo Ferreira Chagas / Manoel Jarbas Vasconcelos Carvalho

do interlocutor de Júlia: "nunca estou menos só do que quando estou só, dizia um antigo; quanto a mim, somente estou só na multidão, onde não posso pertencer nem a ti nem aos outros".

Com essa abordagem proposta acima, cumpre-se a meta de apresentação de um tipo próprio de "remédio" - para lidar-se com o mal - algo que vem figurar, nos textos rousseaunianos sempre, desde as polêmicas geradas em torno de seu Discurso sobre as ciências e as artes, chamado também Primeiro Discurso. Vale-nos destacar o alerta de Jean Starobinski de que, diante da necessidade de esclarecer dúvidas e lacunas de seu escrito inicial, da carreira, ele "jamais deixou de recorrer à metáfora do remédio", porém sugerindo formas diversas de aplicá-los, conforme a emergência imposta virtualmente.

Hoje podemos falar nesses termos da produção do autor, fazendo pouco caso das exigências de originalidade que não poderia ser-lhe própria, nem ao ambiente cultural onde está inserido, mas que justifica a demora que experimentou, ao olhar do mundo atual, para alcançar lugar, efetivamente, no edifício da tradição enquanto filósofo. Pois carecia, segundo lógica da operação com um problema, que permitisse identificar a unidade de sua obra facilmente, que é defendida por ele, notadamente, encontrando-se na unidade natural do homem, perdida com o processo civilizatório, marcado por saltos e quebras periódicas, rupturas, de tempos em tempos, neste percurso, com progressos desastrosos.

Para minimizar isso foi preciso chegar ao século XX e que se tivesse a compreensão mais clara desenvolvida por aqueles que, como Ernst Cassirer, reduzem os supostos efeitos de seu anti-intelectualismo, que não leva Rousseau a aterrissar numa expressão redundantemente sentimental, despropositada, e ressaltando também o erro cometido pelo público ao apreender os diferentes escritos do genebrino, considerandoos, cada um deles, a seu tempo, enquanto corpos isolados, na medida em que seria essencial vê-los como partes do conjunto da produção. Decisivo no auxílio à superação deste impasse, Cassirer foi influente ao escrever o ensaio A questão Jean-Jacques Rousseau (1932), onde comenta que "até numa idade avançada Rousseau não se cansou de defender e afirmar a unidade de sua obra" cumprindo função importante, não tendo, aqui, necessariamente, a revelação que poderia ser entendida enquanto um "excesso de zelo" próprio da busca de "um princípio explicativo geral" para autores

\begin{tabular}{|l|l|l|l|l|}
\hline Gevista Dialectus & Ano 8 & n. 15 & Agosto - Dezembro 2019 & p. 8-17 \\
\hline
\end{tabular}


Arlei de Espíndola / Eduardo Ferreira Chagas / Manoel Jarbas Vasconcelos Carvalho

deste contexto, como pensa Jean Fabre. Pois no importante livro do mesmo momento, e propósito, chamado Filosofia do iluminismo, o pensador neokantiano, malgrado o alvo rechaçado pelo último, mantendo-se em vista, não deixa de se referir aos méritos desta filosofia, mesmo aceitando que seja marcada mais pela síntese das ideias passadas, à medida que vem formar "uma totalidade" em movimento, e é "incansavelmente flutuante, em permanente fluxo", de modo que "não poderia reduzir-se a uma simples soma de opiniões individuais", o que vale claramente para Rousseau.

Por esse modo pouco usual de tratar de filosofia nos padrões clássicos do polêmico e provocativo texto premiado de 1749, o Discurso sobre a origem e os fundamentos da desigualdade entre os homens (1754) é definido por Rousseau enquanto um escrito que o supera, tornando-se um trabalho da maior importância, sendo reconhecido por - a despeito de espantar aqueles que não o leem ainda - Leo Strauss, que o referenda propriamente, tendo-a enquanto a "obra mais filosófica de Rousseau", fazendo-se, segundo o intérprete, aquela que "contém as suas reflexões fundamentais", impondo-se enquanto produção de um "filósofo", trazendo seus princípios básicos, expostos com mais completude, após ultrapassar as implicações que pudessem gerar a ocasião, com este novo concurso.

Rousseau busca apontar, no conjunto, a origem dos problemas desenvolvendo um diagnóstico preciso que é seguido da apresentação de “remédios' enquanto alternativas para contorná-los. Neste caso, após indicar a necessidade, reiteradamente, de estudar-se o homem para falar-se da existência do "direito natural" visando projetar a parte positiva da obra. Pois, considerando este quadro de abandono do plano da natureza de maneira genérica, a proposição da legitimidade política, requerendo a realização do pacto social legítimo, após a caótica realidade inaugurada com a sociedade civilizada, ou dizendo melhor, que eclodi do apogeu, no sentido negativo, do estado de civilização, estabelecido sem a presença do ser, propriamente naturalizado, político e social, depois do estabelecimento da propriedade, persegue o outro passo. Esse agora reside em definir, fundar, a instituição política ideal, concedendo a importância que merece, finalmente, o Do contrato social, ou princípios do direito político (1762), que é um livro, na verdade, que resultou enquanto a parte que se justificava conservar e imprimir do projeto inacabado ao qual se dedicava com muito

\begin{tabular}{|l|l|l|l|l|}
\hline Q Povista Dialectus & Ano 8 & n. 15 & Agosto - Dezembro 2019 & p. 8-17 \\
\hline
\end{tabular}


Arlei de Espíndola / Eduardo Ferreira Chagas / Manoel Jarbas Vasconcelos Carvalho

afinco e expectativa - até se convencer de que não podia realizá-lo completamente que eram suas Instituições políticas, cuja referência aparece no livro IX das Confissões.

Ao Do contrato social, no qual Rousseau pensava fundar o direito político, buscando superar Montesquieu, que se contentou "com tratar do direito positivo dos governos estabelecidos" sendo estes estudos diferentes; mas também estabelecer considerações maiores sobre as relações internacionais, dando o título de "pequeno tratado", reconhecendo-o como o cabe, embora seja visto, pelo público, enquanto seu livro por excelência. E o escrito robusto, produzido simultaneamente, publicado poucas semanas depois, tratando-se do Emílio ou Da educação (1762), chama de "grande tratado" que, ainda que seja menos lido do que o outro hoje, recebe dele toda a consideração. Nele, não só apresenta um resumo do trabalho anterior no seu quinto livro, como reflete sobre todas as questões, de sua obra, passando por educação, ética, política, religião, etc. É verdade que conserva ruptura com o aspecto dogmático do racionalismo, dos philosophes, da filosofia abstrata e teórica, do século anterior, da metafísica inspirada em Descartes, consumando os princípios, por exemplo, de sua ética baseada nos sentimentos, conservando e justificando o valor das paixões, condenando a religião, os excessos da igreja católica, da educação dos jesuítas, etc.

Contudo, o Emílio, na avaliação de Allan Bloom, teria tudo para desfrutar de mais crédito, junto ao público acadêmico, ocupando lugar maior na tradição. Mas trata-se de um livro pouco lido e considerado verdadeiramente, levando-se em conta sua relevância e abrangência teórica, se pensarmos o que acontece com outros textos, de outros escritores, agraciados ou favorecidos pela moda. E mais ainda, às vezes - o que é talvez pior - segue vítima de erros de recepção, havendo frequentes mal-entendidos, com a execução de leituras ruins, tendo prejuízos, ao invés de beneficiar-se, por meio de sua proposta de valorização da infância, esta passagem da vida, nas suas fases de desenvolvimento, não raro negligenciadas, gerando incontornáveis resultados negativos para o futuro daquele que se pretende ver enquanto um indivíduo saudável, ativo, livre, autônomo, responsável, quando chegasse a vida adulta.

Assim, ao leitor atento e assíduo dos escritos, ao pesquisador de seu legado teórico, aquele que se dedica a estudar firmemente a filosofia de Rousseau, tendo, inclusive, extraído proveito para sua experiência, no correr do tempo, maior ou menor na convivência com a reflexão, dos textos, por este carregar a riqueza que se sabe este

\begin{tabular}{|l|l|l|l|l|}
\hline Gevista Dialectus & Ano 8 & n. 15 & Agosto - Dezembro 2019 & p. 8-17 \\
\hline
\end{tabular}


Arlei de Espíndola / Eduardo Ferreira Chagas / Manoel Jarbas Vasconcelos Carvalho

ter, tratando das questões mais centrais, pertinentes, interessantes, na hipótese de que, para os tempos de hoje, não haveria de ser julgada insuficiente, para nenhum tempo, à filosofia, para fazer-se filosofia, livrando-se do preconceito, ter o exercício teórico em torno das questões eminentemente da filosofia prática, assumida declaradamente pelo autor enquanto acertado, é meio caminho para muitos leitores, que requerem a presença da questão do ser, no sentido ontológico, para justificar-se enquanto filosofia.

Conseguimos entender enquanto justificada a posição de Rousseau, fazendo-se em conformidade com o que é próprio da modernidade filosófica, tornandose indicativo favorável, sem até nos surpreender, o crescimento do interesse por Rousseau, por sua obra, impondo-se enquanto fruto, é claro, dos trabalhos que se realiza em nosso meio incansavelmente que se consuma com o aumento das publicações, dos eventos, grupos de trabalhos, confirmando-se com todo este volume de produção, de textos, de qualidade, disponibilizados para fazer parte do presente Dossiê mantendo, o que é mais instigante, interesses variados, gerando a expectativa no leitor de deparar-se com alguns dos remédios, das respostas, que seriam aventadas pelo filósofo, para pensar-se os problemas.

Haveria de causar contentamento ao professor Salinas Fortes, falecido precocemente em 1987, pois seu trabalho muito contribui para esta caminhada, quando o andar era mais tímido na direção do genebrino em nosso meio, no sentido quantitativo, ano em que eu iniciei, casualmente, meus estudos na graduação de filosofia, havendo apostado e investido, nas diferentes frentes de produção teórica, legando-nos trabalhos, também, com o teor introdutório, parecendo desejar a aproximação do público leigo e afastado da universidade até, fazendo-se importante para nós. Salinas, não se fazendo o único, é claro, neste intercurso até o presente, reconheceu sua riqueza, e fertilidade, tendo-se agora este crescimento do interesse em torno de Rousseau ampliado, esperando-se, de nossa parte, ser útil ao afirmar isso, pois soube homenagear o genebrino, exemplarmente, com seus textos, podendo-se colher estes frutos que desejamos não precisar deixar de colher.

Salinas Fortes viu em Rousseau o mais difícil de ser definido dos iluministas, o mais profundo, aquele que precisou que chegasse o século $\mathrm{XX}$, resolvendo-se o impasse, na recepção universal, em torno da suposta falta total de unidade de sua obra, para que começasse a ser efetivamente compreendido, pois era

\begin{tabular}{|l|l|l|l|l|}
\hline Gevista Dialectus & Ano 8 & n. 15 & Agosto - Dezembro 2019 & p. 8-17 \\
\hline
\end{tabular}


Arlei de Espíndola / Eduardo Ferreira Chagas / Manoel Jarbas Vasconcelos Carvalho

aparentemente complicado, difícil de ser definido, e amarrado a rótulos. Trazendo nuances próprias, acompanhando a discussão que era feita, Salinas reconhece nele "mil meandros, abrigando aparentes paradoxos", sugerindo cobrar dos leitores outro nível de exigência. E, completando, o fino leitor, indica que, de fato: "somente em nosso século que Rousseau começa a ser compreendido. Foi somente agora, como ele previa, dizendo que escrevia para a posteridade”. Termina atualmente mostrando-se, então, "em toda a plenitude da sua importância em vários domínios do saber e das artes, desde a literatura até à pedagogia e à política".

Esses trabalhos disponibilizados para o Dossiê Rousseau, atendendo a diferentes aspectos de sua produção, valorizando diferentes remédios propostos pelo filósofo genebrino, que produz, aliás, uma nova versão do iluminismo, confirmam alguns dos tantos interesses teóricos de Rousseau, mesmo que a política não deixe de contar com um lugar de destaque, como sinaliza a célebre passagem das Confissões, estando a tudo relacionada, dependendo do poder instituído o caráter de um povo: "povo nenhum teria natureza diferente daquela que seu governo lhe emprestava". Pois estes diferentes estudos tornar-se-iam alvo de referências e comentários breves, pontuais, mas diretos, no segundo movimento da reflexão deste editorial, visando constituir-se enquanto fonte de estímulo, de incentivo, para o fortalecimento da leitura de Rousseau, eventualmente, de um público que ainda ensaia dele se aproximar de alguma maneira, ou de leitores que o questionam ainda sem proveito, deixando de compreendê-lo, sendo tocado talvez por outro móvel, outro interesse, quem sabe espúrio, com o propósito de banalizá-lo, sem muito ganhar com isso, além daqueles que preferem simplesmente prestigiá-lo, mesmo que lhe tornem objeto de crítica.

Entendemos que este volume presente de produção intelectual, de pesquisas, revela que se tem, já, um maior número de leitores, efetivamente, de Rousseau, havendo a possibilidade de aprimoramento no grau da compreensão, de acerto maior das inferências produzidas, de acordo com o sentido que imprime, fazendo-se a devida homenagem, traduzindo aquilo que é almejado por aqueles que possuem zelo bem medido por sua obra, sem precisarem, com isso, amenizar a crítica ou ver se deturparem o discurso para que sua intensidade e finalidade sejam capitadas, notando-se sua maestria ser justamente beneficiada, admitida, reconhecida. Aqui não temos um sinal de falta do que dizer, pois o reconhecimento não passa pelo ato de fazer-se vistas grossas,

\begin{tabular}{|l|l|l|l|l|}
\hline Govista Dialectus & Ano 8 & n. 15 & Agosto - Dezembro 2019 & p. 8-17 \\
\hline
\end{tabular}


Arlei de Espíndola / Eduardo Ferreira Chagas / Manoel Jarbas Vasconcelos Carvalho

quer dizer, estamos autorizados a interpelar qualquer autor, e nisso tem-se claramente a fonte do reconhecimento também, que foge da prática de mitificar-se a escrita, pensando dar-lhe créditos, dessa forma.

Por esse caminho pode-se despertar o interesse por Rousseau da parte de novos leitores garantindo que ele se situa na origem do florescimento de nossa modernidade filosófica; que ele não é um pensador desvinculado dos problemas em geral que são por nós vividos, tendo-os antecipado teoricamente vários deles.

É preciso, sim, haver paciência e abertura para reconhecer a complexidade de seu pensamento entendendo que ele tem um problema teórico na base de sua especulação e que este problema impõe uma unidade entre pensamento e vida. E isto, mesmo que este problema possa implicar no reconhecimento de um dado hipotético e que seja tratado com outro tipo de escrita, de método, fugindo do encaminhamento tradicional, da lógica, do rigor, implicando o interesse que tem pelo imediato, pelo intuído, pela consideração dos dados da consciência, do sentimento, da voz interior, enquanto fonte de todos os remédios. Pois serve este de núcleo irradiador para o pensar da própria ordem democrática, da soberania popular, baseada na existência da vontade geral, servindo do lugar exato que há de se extrair todos os remédios possíveis, sem dispensar o humano racional, a razão como fonte de sua orientação, pois este seria o papel desta faculdade.

Ora, o móbil espontâneo daí emergente, daí resultante, estende esta intuição às diferentes obras escritas por Rousseau havendo um projeto teórico-filosófico do genebrino, moldado, portanto, à sua maneira passional, no sentido de encontrar a unidade perdida neste movimento de retorno à si mesmo, com o contato com sua interioridade produzindo um encurtamento da distância histórica, fazendo lembrar que se tem o comentário de Henri Gouhier, de Starobinski, neste sentido; podendo-se apenas questionar, então, o modo como é estabelecida a unidade, é definido o retorno à natureza, se tem-se, de fato, aí a natureza. Mesmo que Rousseau seja, segundo Todorov, "um crítico severo da humanidade atual, em nome de um ideal perdido ", não teríamos nele um primitivista, um regressivista; e ainda que flerte, confabule, com o isolamento, a vida retirada, pela qual se alcança o ganho de viver-se o sentimento da existência, parecendo-nos informar igualmente seu projeto teórico, sua escrita o apresenta, mas sem poder apagar, anular o paradoxo, a ambiguidade, que marca presença na natureza das

\begin{tabular}{|l|l|l|l|l|}
\hline Govista Dialectus & Ano 8 & n. 15 & Agosto-Dezembro 2019 & p. 8-17 \\
\hline
\end{tabular}


Arlei de Espíndola / Eduardo Ferreira Chagas / Manoel Jarbas Vasconcelos Carvalho

coisas, não representando esta algo de necessariamente negativo. Esta via é colocada entre os outros planos alternativos, dentre os quais se costuma destacar os das esferas sociais e políticas, quer dizer, oferecendo a prioridade destes outros remédios, ligados ao plano público. Mas a escrita confessional, o autorretrato, a vida retirada, a busca do autoconhecimento, a fala na primeira pessoa, a reivindicação da liberdade no contato com a natureza, é uma característica da escrita de Rousseau, não representando uma patologia, uma fuga, necessariamente.

Isso permite que se compreenda, inclusive, que o iluminismo, a ilustração, incluindo a escrita de Rousseau nela mesma, não é uniforme, destituindo-a de suposta falta de riqueza, como dá-se também com os outros autores, conforme é o protesto de da crítica especializada, de Cassirer, de Starobinski, de Salinas, dentre outros. Ante aquele julgamento condenável, que produz um equívoco, fazendo-se em verdade, estes últimos, impulsionados, como Rousseau, pela multiplicidade de ideias produzida seja pelo dinamismo histórico, seja em Rousseau, especialmente, também pela existência humana marcada pelo dinamismo e perfectibilidade.

O caráter formal, que se colocaria enquanto intrínseco ao pensamento, perderia assim força, a simplicidade em sentido intelectual, cairia por terra abrindo espaço para aceitar-se que vai seguir havendo um Rousseau aberto em suas ideias, sem possibilidades de ser entendido facilmente, e para todo o sempre, mas capaz de ecoar com as leituras, tornando-se referência para lançar luzes sobre os enigmas e imbróglios no presente podendo partir dele intuições úteis e necessárias conforme a aproximação que se realize, interpelando-o ou sendo tocado por algo que nos desperte, levando-nos até ele, num movimento em que se permite o fazer-se enquanto historiador da filosofia ou mesmo certificando-nos de sua atualidade, de acordo com a demanda que a vida vem apresentar, dando sentido em a ele recorrer, pois a atualidade não pode ser medida necessariamente pela cronologia do texto, mas também pela abertura ao despertar que move o filosofar, esta via de mão dupla, não sendo plausível uma conexão que se reduz aos livros, se há vida propriamente, ainda que toda a riqueza de um clássico seja possível.

O trabalho dialogal, de avaliação do sentido, de crítica efetiva, está autorizado pela filosofia do iluminismo na versão de Rousseau, pois é preferível ser paradoxal, indica o Emílio, do que se aterrissar no preconceito. Precisamos da presença

\begin{tabular}{|l|l|l|l|l|}
\hline Q Povista Dialectus & Ano 8 & n. 15 & Agosto-Dezembro 2019 & p. 8-17 \\
\hline
\end{tabular}


Arlei de Espíndola / Eduardo Ferreira Chagas / Manoel Jarbas Vasconcelos Carvalho

do desejo, das paixões, a fim de evitar o mergulho na conduta automatizada e mecânica que se completa no seu dito de que: "somente a paixão nos faz agir", fazendo defesa de sua subsistência. Apesar de aqui não se tratar de exclusão da responsabilidade individual diante do chamado de escolher-se, para elevar a graduação de nossa liberdade, tornando-nos morais, que se apresenta enquanto uma conquista a ser estabelecida, o que não significa formalidade, negativa do movimento, do dinamismo da vida. Agora: “como apaixonar-se por interesses que ainda não se tem?". Ao pensar que nos cabe o bem-estar, a felicidade, entendamos que o desafio ao alcance está em estabelecer uma vida em comum que seja razoável. Remediar problemas implica em reconhecer, com Rousseau, o paradoxo, de que este brota da mesma fonte que o gera:

Pois, nossa vida conta com este dilema: "se algum ser imperfeito pudesse bastar-se a si mesmo, de que gozaria segundo nós? Seria só e miserável. Não concebo quem não precisa de nada possa amar alguma coisa; não concebo que quem não ama nada possa ser feliz". Fraqueza, sociabilidade e humanidade, pois, se conjugariam, ainda que não possamos dizer que a alternativa da vida retirada, da literatura, seja um sinal de prepotência.

Segue-se o editorial com o direto contato com os textos do Dossiê Rousseau, que perfazem, aliás, o montante de 21 artigos, além do trabalho de tradução, com os quais encontramos nossa fonte de estímulo, e de alento, para levar em frente o projeto, guardando-se a expectativa de que todos que prestigiam esta produção possam tirar proveito, desfrutando de boa leitura e reflexão!

\begin{tabular}{|l|l|l|l|l|}
\hline Q Rovista Dialectus & Ano 8 & n. 15 & Agosto - Dezembro 2019 & p. 8-17 \\
\hline
\end{tabular}

